\title{
Standardization of Administered Activities in Pediatric Nuclear Medicine: A Report of the First Nuclear Medicine Global Initiative Project, Part 2-Current Standards and the Path Toward Global Standardization
}

\begin{abstract}
Frederic H. Fahey ${ }^{1}$, Henry Hee-Seung Bom ${ }^{2}$, Arturo Chiti ${ }^{3}$, Yun Young $\mathrm{Choi}^{4}$, Gang Huang ${ }^{5}$, Michael Lassmann ${ }^{6}$, Norman Laurin ${ }^{7}$, Fernando Mut ${ }^{8}$, Rodolfo Nuñez-Miller ${ }^{9}$, Darin O'Keeffe ${ }^{10}$, Prasanta Pradhan ${ }^{11}$, Andrew M. Scott ${ }^{12}$, Shaoli Song ${ }^{13}$, Nischal Soni ${ }^{14}$, Mayuki Uchiyama ${ }^{15}$, and Luis Vargas ${ }^{16}$

${ }^{1}$ Department of Radiology, Boston Children's Hospital, Harvard Medical School, Boston, Massachusetts; ${ }^{2}$ Department of Nuclear Medicine, Chonnam National University Hwasun Hospital, Hwasun Jeonnam, Republic of Korea; ${ }^{3}$ Department of Biomedical Sciences, Humanitas Research Hospital, Rozzano, Italy; ${ }^{4}$ Department of Nuclear Medicine, Hanyang University Hospital, Seoul, Republic of Korea; ${ }^{5}$ Department of Nuclear Medicine, Ren Ji Hospital, School of Medicine, Shanghai Jiaotong University, Shanghai, China; ${ }^{6}$ Department of Nuclear Medicine, University Würzburg, Würzburg, Germany; ${ }^{7}$ Department of Nuclear Medicine, Centre Hospitalier Affilié Universitaire Régional de Trois-Rivières, Quebec, Canada; ${ }^{8}$ Department of Nuclear Medicine, Spanish Association Hospital, Montevideo, Uruguay; ${ }^{9}$ Section of Nuclear Medicine and Diagnostic Imaging, International Atomic Energy Agency, Vienna, Austria; ${ }^{10}$ Department of Medical Physics and Bioengineering, Christchurch Hospital, Christchurch, New Zealand; ${ }^{11}$ Department of Nuclear Medicine, Sanjay Gandhi Post Graduate Institute of Medical Sciences, Lucknow, India; ${ }^{12}$ Department of Molecular Imaging and Therapy, Austin Hospital, and Olivia Newton-John Cancer Research Institute and School of Cancer Medicine, La Trobe University, Melbourne, Australia; ${ }^{13}$ Department of Nuclear Medicine, Ren Ji Hospital, School of Medicine, Shanghai Jiaotong University, Shanghai, China; ${ }^{14}$ Department of Nuclear Medicine, Inkosi Albert Luthuli Central Hospital, DurbanKwaZulu, Durban, South Africa; ${ }^{15}$ Department of Radiology, Jikei University School of Medicine, Tokyo, Japan; and ${ }^{16}$ Department of Nuclear Medicine, Xalapa Medical Center, Xalapa, Mexico
\end{abstract}

The Nuclear Medicine Global Initiative (NMGl) was formed in 2012 and consists of 13 international organizations with direct involvement in nuclear medicine. The underlying objectives of the NMGI are to promote human health by advancing the field of nuclear medicine and molecular imaging, encourage global collaboration in education, and harmonize procedure guidelines and other policies that ultimately lead to improvements in quality and safety in the field throughout the world. For its first project, the NMGl decided to consider the issues involved in the standardization of administered activities in pediatric nuclear medicine. It was decided to divide the final report of this project into 2 parts. Part 1 was published in this journal in the spring of 2015. This article presents part 2 of the final report. It discusses current standards for administered activities in children and adolescents that have been developed by various professional organizations. It also presents an evaluation of the current practice of pediatric nuclear medicine specifically with regard to administered activities as determined by an international survey of 313 nuclear medicine clinics and centers from 29 countries. Lastly, it provides recommendations for a path toward global standardization of the administration of radiopharmaceuticals in children.

Received Nov. 13, 2015; revision accepted Mar. 2, 2016.

For correspondence or reprints contact: Frederic H. Fahey, Division of Nuclear Medicine and Molecular Medicine, Boston Children's Hospital, 300 Longwood Ave., Boston, MA 02115.

E-mail: frederic.fahey@childrens.harvard.edu

Published online Mar. 31, 2016.

COPYRIGHT (c) 2016 by the Society of Nuclear Medicine and Molecular Imaging, Inc.
Key Words: pediatrics; administered activity; dosimetry

J Nucl Med 2016; 57:1148-1157

DOI: 10.2967/jnumed.115.169714

T n the summer of 2012, several international organizations directly involved in the practice and science of nuclear medicine decided to engage in a project of common interest for the betterment of the field worldwide. The underlying objectives were to promote human health by advancing the field of nuclear medicine and molecular imaging, encourage global collaboration in education, and harmonize procedure guidelines and other policies that ultimately lead to improvements in quality and safety in the field throughout the world. This endeavor was named the Nuclear Medicine Global Initiative (NMGI) and includes societies from various countries as well as several multinational organizations in the field of nuclear medicine (Table 1).

The group decided that the first NMGI project would be to consider the issues involved in the standardization of administered activities in pediatric nuclear medicine. Part 1 of this report described the reasons for the choice of project (1). It also provided a review of the value of pediatric nuclear medicine, the current understanding of the carcinogenic risk of radiation as it pertains to the administration of radiopharmaceuticals in children, and the application of dosimetric models in children. Gaps in current knowledge on these topics were also discussed. A listing of pertinent educational and reference resources, available in print and online, was provided and described. 
TABLE 1

NMGI Participants

\begin{tabular}{|c|c|}
\hline Institution & Participant \\
\hline $\begin{array}{l}\text { Asia and Oceania Federation } \\
\text { of Nuclear Medicine and } \\
\text { Biology }\end{array}$ & $\begin{array}{l}\text { Henry Hee-Seung } \\
\text { Bom }\end{array}$ \\
\hline $\begin{array}{l}\text { Australian and New Zealand } \\
\text { Society of Nuclear Medicine }\end{array}$ & $\begin{array}{l}\text { Darin O'Keeffe, } \\
\text { Andrew Scott }\end{array}$ \\
\hline $\begin{array}{l}\text { Canadian Association of Nuclear } \\
\text { Medicine }\end{array}$ & Norman Laurin \\
\hline $\begin{array}{l}\text { Chinese Society of Nuclear } \\
\text { Medicine }\end{array}$ & $\begin{array}{l}\text { Shaoli Song, } \\
\text { Gang Huang }\end{array}$ \\
\hline $\begin{array}{l}\text { European Association of Nuclear } \\
\text { Medicine }\end{array}$ & $\begin{array}{l}\text { Arturo Chiti, Michael } \\
\text { Lassmann }\end{array}$ \\
\hline $\begin{array}{l}\text { International Atomic Energy } \\
\text { Agency }\end{array}$ & $\begin{array}{l}\text { Rodolfo } \\
\text { Nuñez-Miller }\end{array}$ \\
\hline $\begin{array}{l}\text { Japanese Society of Nuclear } \\
\text { Medicine }\end{array}$ & Mayuki Uchiyama \\
\hline $\begin{array}{l}\text { Korean Society of Nuclear } \\
\text { Medicine }\end{array}$ & Yun Young Choi \\
\hline $\begin{array}{l}\text { Latin American Association of } \\
\text { Societies of Nuclear Medicine } \\
\text { and Biology }\end{array}$ & Fernando Mut \\
\hline Society of Nuclear Medicine India & Prasanta Pradhan \\
\hline $\begin{array}{l}\text { Society of Nuclear Medicine and } \\
\text { Molecular Imaging }\end{array}$ & Frederic Fahey \\
\hline $\begin{array}{l}\text { South African Society of Nuclear } \\
\text { Medicine }\end{array}$ & Nischal Soni \\
\hline $\begin{array}{l}\text { World Federation of Nuclear } \\
\text { Medicine and Biology }\end{array}$ & Luis Vargas \\
\hline
\end{tabular}

This part 2 describes the findings and conclusion of the first NMGI project. It also provides an in-depth description of the current standards for administered activities in children and adolescents that have been developed by various organizations. An evaluation of the current practice of pediatric nuclear medicine, specifically with regard to administered activities as determined by an international survey of nuclear medicine clinics and centers, is also included. Lastly, the report recommends a path toward global standardization of the administration of radiopharmaceuticals in children.

\section{CURRENT STANDARDS FOR PEDIATRIC ADMINISTERED ACTIVITIES}

Optimization of pediatric administered activity is a complex process of risk versus benefit that is further complicated by the clinical requirements of the examination being performed; variations in physiologic uptake of the radiopharmaceutical, patient attenuation, and patient positioning; the counting statistics of static versus dynamic imaging; whether pediatric sedation is used and its influence on imaging time; the spatial resolution and sensitivity of the imaging system; the reconstruction and filtering algorithms; and the risk associated with the radiation dose (2-7). The development of an objective measure of the performance of an imaging procedure for any given administered activity is challenging. Thus, the nuclear medicine community may rely on tools such as surveys that use the collective experience of the community to help develop guidelines and standardize administered activities. However, some such surveys have shown large variations in practice, resulting in a necessary focus on dedicated pediatric facilities for consistent findings (8); even then, disparities have been found (9), and such findings were used to initiate development of the 2010 North American Consensus Guidelines $(10,11)$.

A review of the literature and discussions within the NMGI confirmed that there were 4 main guidelines on pediatric administered activity currently in use: the 2010 North American Consensus Guidelines $(10,11)$, the European Association of Nuclear Medicine (EANM) dosage card (12-14), the Japanese Society of Nuclear Medicine (JSNM) guidelines (15), and the Administration of Radioactive Substances Advisory Committee (ARSAC) "Notes for Guidance on the Clinical Administration of Radiopharmaceuticals and Use of Sealed Radioactive Sources" (revised 2014) (16). The ARSAC notes will not be discussed because the scaling factor from adult administered activity to pediatric administered activity used in the ARSAC document is based on an older version of the EANM guidelines. A comparison of the ARSAC pediatric administered activity schedule with a more recent EANM dosage card has already been presented by Rixham and Roberts (17). The North American group and the EANM recently published "harmonized" guidelines $(18,19)$.

\section{EANM Dosage Card (2007 and 2014)}

The EANM guidelines started with a report by Piepsz et al., who presented a radiopharmaceutical schedule for an adult-to-pediatric scaling factor that was based on body surface area calculated from patient weight based on the practice at 4 institutions (20). These scaling factors were subsequently studied by Jacobs et al., who investigated whether the factors gave weight-independent effective doses or weight-independent counting rates (21). They concentrated their analysis on the effective dose variation with weight and performed a cluster analysis that found 3 significant clusters, called A, $\mathrm{B}$, and $\mathrm{C}$, that represented the weight variation. Cluster A corresponded to renal imaging agents, cluster $\mathrm{C}$ to thyroid imaging using radioiodine, and cluster $\mathrm{B}$ to most of the other radiopharmaceuticals.

This clustering approach was used by Lassmann et al. to develop the EANM pediatric dosage card, with each radiopharmaceutical being placed in 1 of the 3 clusters (A, B, or C). Each radiopharmaceutical had a corresponding minimum activity and baseline activity that was scaled by body weight to give the administered activity (12). Instead of using the previous approach, which applied a scaling factor to an adult activity, Lassmann et al. presented minimum activities and baseline activities that were developed by the Pediatric and Dosimetry Committee of the EANM for good practice. These baseline values meant that the administered activities were not directly related to adult reference levels. The committee advised, however, that the calculated activities should be capped if the scaling by weight resulted in an activity that exceeded national diagnostic reference levels for a radiopharmaceutical.

The 2007 EANM dosage card subsequently underwent minor corrections (14) and was extended with additional notes for ${ }^{18} \mathrm{~F}-\mathrm{FDG}$ (13). This was recently updated to the 2014 EANM dosage card to harmonize with the North American Consensus Guidelines (18).

\section{North American Consensus Guidelines (2010 and 2014)}

A 2007 survey of 13 specialized pediatric hospitals showed significant variations in the administered activity for pediatric patients (9). This finding led to a partnership between the Image 
Gently campaign, the Society of Nuclear Medicine and Molecular Imaging (SNMMI), the Society for Pediatric Radiology, and the American College of Radiology. Several joint workshops resulted in the development of the 2010 North American Consensus Guidelines for 11 commonly used radiopharmaceuticals $(10,11)$. These guidelines use adult reference activities that are scaled by body weight (except for gastric emptying and cystography), minimum administered activities (except for cystography), and maximum administered activities for ${ }^{99 \mathrm{~m}}$ Tc-mercaptoacetyltriglycine (MAG3), ${ }^{123}$ I-metaiodobenzylguanidine (MIBG), cystography, and gastric emptying. For several of the procedures, the guidelines advise that the EANM 2007 dosage card may be used instead of the recommended parameters. An important difference between the EANM dosage card and the North American Consensus Guidelines is that the latter advocates the use of a linear weight adjustment of the administered activity, whereas the EANM scaling by body weight is nonlinear for all classes. The basis for the linear weighting is that when the administered activity for single-photon emitting radiopharmaceuticals is adjusted on the basis of patient weight, the count density varies little from infancy to adolescence (i.e., a range of patient weights and ages). The guideline uses this relationship combined with weight-based scaling from an adult reference activity. Use of the 2010 North American Consensus Guidelines results in a slightly lower administered activity for infants and small children than was recommended on the 2007 EANM dosage card except for ${ }^{99} \mathrm{~m}$ Tc-dimercaptosuccinic acid (DMSA) scans and $\mathrm{Na}^{18} \mathrm{~F}$ scans, in which the doses are much lower than on the 2007 EANM dosage card (Fig. 1) (22). These guidelines were recently updated to the 2014 North American Guidelines to harmonize with the EANM dosage card (18). These harmonized guidelines do not exactly agree in all instances because the respective guidelines continue to use different dosage-calculation approaches.

\section{Japanese Society of Nuclear Medicine (JSNM) Guidelines (2014)}

Parts 1 and 2 of the JSNM consensus guidelines for pediatric nuclear medicine have been translated into English (15). These guidelines were developed by the JSNM Optimization Committee

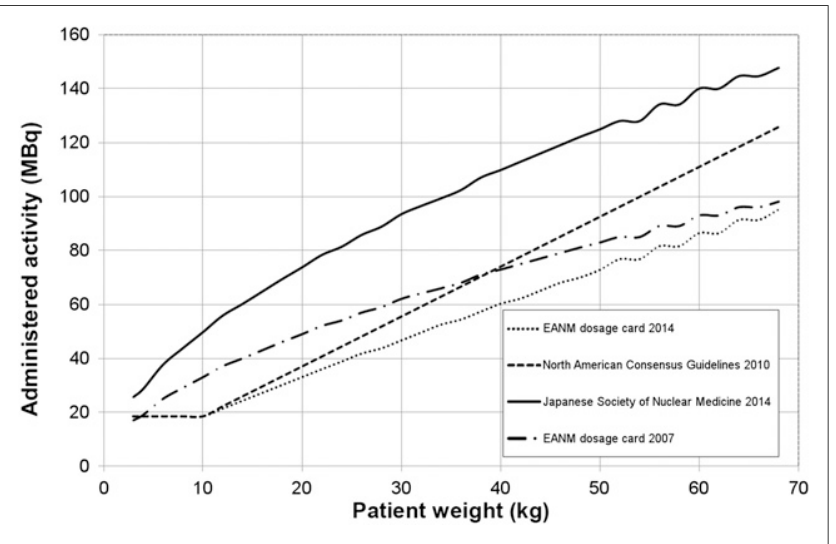

FIGURE 1. Comparison of $99 \mathrm{mTC}$-DMSA pediatric administered activity guidelines from 2014 EANM dosage card, 2014 JSNM guidelines, 2007 EANM dosage card, and 2010 North American Consensus Guidelines. This is an example of the large difference between the 3 guidelines for some radiopharmaceuticals, although for smaller children, 2014 EANM dosage card agrees better than 2007 EANM dosage card with 2010 North American Consensus Guidelines. for Pediatric Nuclear Medicine and were based on a survey of 14 Japanese institutions (23). The guidelines are based on the EANM class, baseline activity, and minimum activity, with weight-based multipliers for each class of radiopharmaceutical. However, the JSNM modified the EANM dosage card to develop a JSNM dosage card for 24 radiopharmaceuticals (15). The JSNM dosage card is significantly different from the EANM dosage card for ${ }^{99 \mathrm{~m}} \mathrm{Tc}-$ DMSA, ${ }^{99 m}$ Tc-MAG3, $99 \mathrm{~m}$ Tc-macroaggregated albumin, and 99m Tc-setamibi, with the JSNM recommending slightly higher activities. There are also some significant differences from the North American Consensus Guidelines for ${ }^{99 \mathrm{~m}} \mathrm{Tc}-\mathrm{MAG} 3,{ }^{99 \mathrm{~m}} \mathrm{Tc}-$ methyldiphosphonate (MDP) in older children, ${ }^{99 \mathrm{~m} T c-D M S A}$, ${ }^{123} \mathrm{I}-\mathrm{MIBG}$, and ${ }^{18} \mathrm{~F}$.

\section{Comparison of the Guidelines and a Move Toward Harmonization}

There are two common components of the main guidelines for pediatric administered activity. For most of the radiopharmaceuticals, each guideline lists the minimum activity required to prevent a substandard examination. All 3 guidelines adjust the administered activity according to patient weight. Although the use of weight-based activity adjustment has been debated, it has remained a popular approach $(2,20,24,25)$. The North American Consensus Guidelines recommend linear scaling by weight because this results in a small variation in counts per unit area from infancy to adolescence. However, preservation of counts may result in a significant increase in effective dose to some children. The alternative method that preserves effective dose rather than counts may be considered although this could lead to substandard imaging in some cases due to low counts (21). All 3 guidelines recommend minimum activities, with significant differences for some of the radiopharmaceuticals. In general, the minimum activity is based on experience rather than science. There is particular concern that PET/CT minimum activities may be too high and that it may be possible to reduce the radiation dose to our smallest patients $(26,27)$.

The EANM dosage card and North American Consensus Guidelines have been harmonized, as recently reported (18). Figure 1 illustrates some changes to the EANM dosage card for ${ }^{99 m}$ Tc-DMSA as a result of this harmonization, with the 2014 EANM dosage card and consensus guidelines now producing similar activities. An important aspect of the harmonization is the scaling factors used for weight-based corrections. If the EANM class A renal imaging radiopharmaceuticals are considered separately, then the scaling factors for classes $\mathrm{B}$ and $\mathrm{C}$ are approximately linear for children weighing more than $10 \mathrm{~kg}$ (Fig. 2). This means that the administered activity for a significant number of children could be modeled as a linear weight-based function, similar to the North American Consensus Guidelines, although with a different offset that could reflect a minimum activity. One of the arguments against adoption of the EANM dosage card is the complexity of applying the method and the chance of an error. However, it can easily be programmed into a spreadsheet or a computer application since the calculation is, in general, fairly straightforward. The EANM and the SNMMI have developed web-based tools and smartphone applications that can be used by nuclear medicine clinics to perform the calculations and determine the recommended administered activity for their pediatric patients (www.snmmi.org/ pedactivitytool or http://www.eanm.org/publications/dosage_calculator. php?navId=285). 


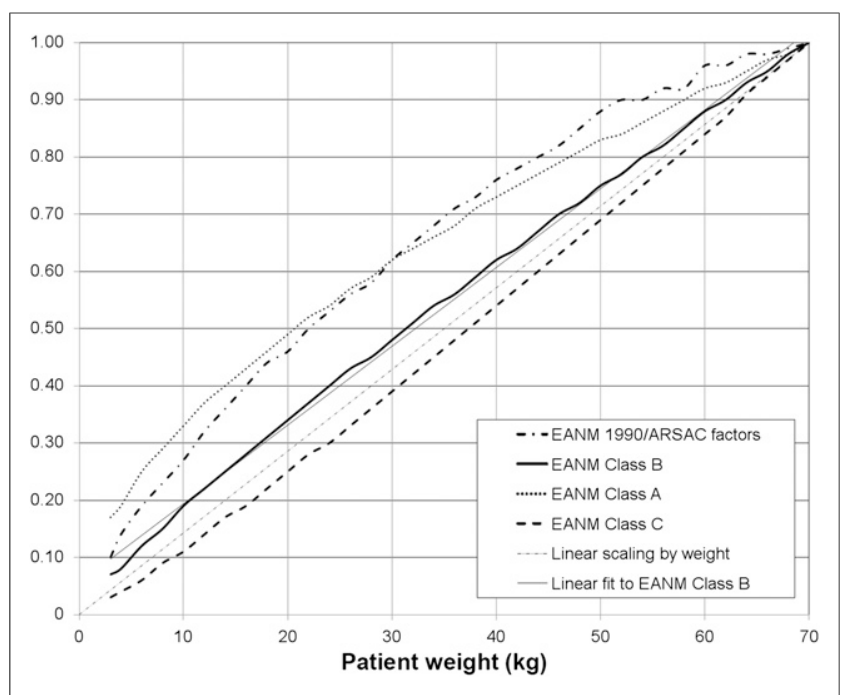

FIGURE 2. 2007 EANM dosage card scaling factors as derived from Jacobs et al. (21) compared with EANM 1990/ARSAC scaling factors and linear weighting factor, for renal imaging. EANM classes $B$ and $C$ are remarkably linear except for small patients, as illustrated by linear trend line fitted to class B. Class A scaling factors are nonlinear.

\section{VARIATIONS IN THE PRACTICE OF PEDIATRIC NUCLEAR MEDICINE}

\section{Previous Surveys}

Survey of North American Pediatric Institutions (2007 and 2013). A survey of dedicated pediatric institutions in North America was performed in 2007 regarding their approach to determining administered activities in smaller patients for 16 nuclear medicine procedures commonly performed on children (9). For each procedure, the institutions were asked if they modified the amount of administered activity by patient size and, if so, by what method. They were also asked about the maximum activity they would administer to a large child (e.g., $>70 \mathrm{~kg}$ ) and the minimum activity they set as a limit for very small patients. If an institution indicated that it modified the administered activity according to the patient's body weight, it was asked to provide the activity per weight (in $\mathrm{MBq} / \mathrm{kg}$ or $\mathrm{mCi} / \mathrm{kg}$ ).

Thirteen dedicated pediatric institutions responded to the survey. Most of the institutions scaled the administered activity by body weight for smaller patients. In general, there was a reasonably wide variation in the values reported across the institutions. The maximum activity and the activity per kilogram varied on average across procedures by about a factor of 3 and for a single procedure by a factor of 10 . The variability in minimum activity was even greater, varying on average by a factor of 10 and by as much as a factor of 20 in a single case. Consider ${ }^{99 m}$ Tc-DMSA renal scanning as a typical case. One institution indicated that it administered $1.11 \mathrm{MBq} / \mathrm{kg}$, whereas another used $3.70 \mathrm{MBq} / \mathrm{kg}$. For minimum activity, one institution indicated a limit of 5.55 $\mathrm{MBq}$, whereas another used $74 \mathrm{MBq}$. The variability for some of the procedures was considerably greater than this. This level of variability became a topic of discussion among the North American pediatric nuclear medicine community, eventually leading to the development and publication of the North American Consensus Guidelines of administered doses for children and adolescents, which were adopted by the SNMMI, the American
College of Radiology, and the Society for Pediatric Radiology and promoted by the Image Gently campaign $(10,11)$.

A follow-up survey of the same 13 pediatric institutions was conducted in 2013. In the intervening $6 \mathrm{y}$, the results of the initial survey had been published, the North American Consensus Guidelines had been approved and published, and Image Gently had run a "Go with the Guidelines" public relations campaign that sought to deliver a poster containing a table of the guidelines to every nuclear medicine clinic in North America (28). All 13 sites that completed the initial survey completed the follow-up as well. The following pertains to the 8 procedures in the survey that also were included in the North American guidelines. For the maximum activity in larger children, the median value across institutions was reduced for 4 procedures, remained the same for 4 procedures, and was consistent with the North American guidelines in both cases in which a maximum activity was defined. The median of the minimum activity for very small patients was reduced for 3 procedures, remained the same for 5 procedures, and was consistent with the North American guidelines for 5 of the 8 procedures. For those that scaled the administered activity by weight for children, the median was reduced for 7 procedures, remained the same for 1 procedure, and was consistent with the North American guidelines for 5 of the 8 procedures. All 13 institutions indicated that they were familiar with Image Gently and the North American guidelines. Ten of the 13 institutions stated that they modified their administered activities according to the North American guidelines.

A survey of 194 general hospitals in the United States regarding the practice of pediatric nuclear medicine was recently performed. This survey included hospitals with more than 300 beds and excluded dedicated pediatric, military veteran, orthopedic, and psychiatric hospitals. The survey included questions that categorized the size of the hospital and whether it was a community or teaching hospital. It also asked whether the hospital performed imaging of children and how the administered activity for smaller children was determined for 5 procedures commonly performed on children $\left({ }^{99} \mathrm{~m} \mathrm{Tc}-\mathrm{MDP}\right.$ bone scans, ${ }^{99 \mathrm{~m}} \mathrm{Tc}-\mathrm{MAG}$ renal studies, ${ }^{99 \mathrm{~m}} \mathrm{Tc}-\mathrm{DMSA}$ renal studies, hepatobiliary studies with ${ }^{99 \mathrm{~m}} \mathrm{Tc}-$ labeled iminodiacetic acid [IDA] derivatives, and ${ }^{18} \mathrm{~F}-\mathrm{FDG}$ PET). A total of 121 hospitals responded to the survey ( $62 \%$ response rate): $50 \%$ were in an urban setting, $51 \%$ described themselves as "community, teaching" hospitals, and $80 \%$ indicated that they performed nuclear medicine studies on children. Of the institutions that performed nuclear medicine studies on children, $86 \%$ performed ${ }^{99 \mathrm{~m}} \mathrm{Tc}-\mathrm{MDP}$ bone scans, $69 \%$ performed ${ }^{99 \mathrm{~m}} \mathrm{Tc}-\mathrm{MAG}$ renal studies, $59 \%$ performed ${ }^{99 m}$ Tc-DMSA renal studies, $39 \%$ performed hepatobiliary studies with ${ }^{99 \mathrm{~m}} \mathrm{Tc}$-labeled IDA derivatives, and $30 \%$ performed ${ }^{18} \mathrm{~F}$-FDG PET studies. Essentially all of the hospitals indicated that they scaled the administered activity for smaller patients by body weight. In all cases but one (maximum activity for ${ }^{99 \mathrm{~m}} \mathrm{Tc}-\mathrm{MAG} 3$ renal scans of $222 \mathrm{MBq}$ rather than the guideline value of $148 \mathrm{MBq}$ ), the median values across the institutions were consistent with the North American guidelines, although there tended to be a reasonable amount of variability on either side of the median value. In addition, $83 \%$ of the respondents were familiar with the Image Gently campaign, $58 \%$ were familiar with the North American guidelines, and 55\% modified their administered activities on the basis of the North American guidelines.

Survey of Korean Institutions (2013). A survey of administered radioactivity for 13 nuclear medicine procedures commonly performed on pediatric patients was conducted at the university-affiliated 
hospitals in South Korea in 2013. The institutions were asked 3 questions. The first was whether they modified the amount of administered radioactivity in pediatric patients and, if so, the selected method or calculation equation. The second was about the maximum and minimum activity for large and very small patients, respectively, for each procedure. The third was whether there were any special considerations for children younger than 1 y old. Sixteen institutions responded to the survey. There was a wide variation in the scaling methods based on body weight (body weight $\times$ equation constant for each procedures) or age (adult dose $\times[$ age +1$] /[$ age +7$]$ ), and some of the institutions used several guidelines, including the EANM dosage card, the Gilday chart, the Korean Society of Nuclear Medicine manual, and so on. The maximum and minimum activity varied considerably (Table 2). Special considerations for children younger than 1 y old included minimizing the administered radioactivity and increasing the acquisition time, sedating the child during the procedure to prevent failure due to motion, paying careful attention to aseptic preparation of radiopharmaceuticals because of the lower immunity of infants, and adding more saline to dilute radiopharmaceuticals, which could minimize the amount of remaining radioactivity in the syringe.

\section{NMGI International Survey}

Based on a review of the current standards for pediatric administered activities, the results of the previous surveys, and discussion within the NMGI working group, it was clear that there were significant variations in the administered activities used in the current practice of pediatric nuclear medicine imaging. Although there has been significant work toward standardization of administered activities by groups such as the SNMMI, EANM, and JSNM, opportunities remain for further improvement and harmonization of the standards worldwide. An international survey on pediatric administered activities was developed to determine whether the 3 main standards were being followed correctly and in their entirety, whether facilities selected one standard over another to meet their local requirements or interest, whether other guidelines existed, and whether facilities were developing local practice guidelines. Furthermore, the survey asked about the most frequent imaging procedures being performed, in order to determine whether there was any variation between developed and developing countries. These questions were addressed using the collective strength of the NMGI to coordinate international participation in the survey and ensure penetration of the survey into several countries to collect a representative worldwide sample of pediatric nuclear medicine imaging practice.

Description of the Survey and Its Implementation. The NMGI survey was a modification of a preexisting survey designed to determine whether sites were following the 2010 North American Consensus Guidelines. The modifications included additional capture of data on the top 5 pediatric imaging procedures performed by a facility (as chosen from a list of 12 procedures, including an "other" option), the guideline that was being followed (if any), and either the typical administered activity or the method of adjusting the activity for individual patients. Facilities that are not dedicated to pediatric imaging may find it difficult to see a sufficient number of pediatric patients to cover a range of procedures. For this reason, the survey questions about administered activity were based on the usual operating protocols rather than on actual patients. The survey asked for details about the $\gamma$-camera, whether SPECT is typically performed, and whether SPECT/CT is performed occasionally. The survey also inquired about the administered activities for a hypothetical 5-y-old boy (20 kg and $110 \mathrm{~cm}$ tall) and 10-y-old girl (30 kg and $140 \mathrm{~cm}$ tall) as a quality control check on whether a facility that claimed to be following a guideline was actually doing so. For facilities performing PET or PET/CT imaging, the survey asked about the administered activity for whole-body pediatric ${ }^{18} \mathrm{~F}-\mathrm{FDG}$ imaging and details on the CT acquisition for PET/CT.

TABLE 2

Minimum and Maximum Administered Doses in Korean Children for 15 University Hospitals

\begin{tabular}{|c|c|c|c|c|}
\hline \multirow[b]{2}{*}{ Radiopharmaceutical } & \multicolumn{2}{|c|}{ Minimum } & \multicolumn{2}{|c|}{ Maximum } \\
\hline & Median (MBq) & Respondents ( $n$ ) & Median (MBq) & Respondents $(n)$ \\
\hline 99mTc-DMSA & $29.6(14.8-74.0)$ & 14 & $129.5(92.5-370.0)$ & 12 \\
\hline 99mTc-MAG3 & $37.0(14.8-111.0)$ & 14 & $185.0(74.0-555.0)$ & 12 \\
\hline 99mTc-MDP & $74.0(22.2-185.0)$ & 13 & $555.0(370.0-1480)$ & 12 \\
\hline 99mTc-diisopropyl-IDA & $37.0(18.5-74.0)$ & 11 & $185.0(111.0-370.0)$ & 10 \\
\hline 123I-MIBG & $37.0(18.5-81.4)$ & 7 & $185.0(74.0-333.0)$ & 7 \\
\hline 99mTc (Meckel diverticulum) & $42.6(9.3-74.0)$ & 12 & $222.0(74.0-555.0)$ & 12 \\
\hline 99mTc (thyroid) & $37.0(10.0-74.0)$ & 13 & $138.8(79.9-370.0)$ & 12 \\
\hline 123| (thyroid) & $11.1(3.0-111.0)$ & 6 & $74.0(20.0-185.0)$ & 7 \\
\hline${ }^{99 m T C-e x a m e t a z i m e ~ o r ~ E C D ~}$ & 99.9 (37.0-222.0) & 14 & $647.5(18.5-1665)$ & 12 \\
\hline 99mTc-setamibi & $95.5(37.0-185.0)$ & 6 & $740.0(259.0-1110.0)$ & 8 \\
\hline${ }^{99 m T c}$ denatured RBCs & 28.5 (18.5-79.9) & 12 & 277.5 (40.0-925.0) & 10 \\
\hline${ }^{67} \mathrm{Ga}$ (tumor) & $11.1(10.0-37.0)$ & 5 & 79.9 (74.0-296.0) & 5 \\
\hline${ }^{18} \mathrm{~F}-\mathrm{FDG}$ & $74.0(37.0-185.0)$ & 13 & $370.0(185.0-555.0)$ & 10 \\
\hline
\end{tabular}


TABLE 3

Distribution of Surveys by Country

\begin{tabular}{|c|c|}
\hline Country & Sites $(n)$ \\
\hline Albania & 1 \\
\hline Australia & 46 \\
\hline Belgium & 7 \\
\hline Canada & 8 \\
\hline Chile & 1 \\
\hline China & 33 \\
\hline Croatia & 1 \\
\hline Czech Republic & 7 \\
\hline Denmark & 2 \\
\hline Germany & 4 \\
\hline Hungary & 6 \\
\hline Israel & 11 \\
\hline Italy & 21 \\
\hline Japan & 98 \\
\hline Malta & 1 \\
\hline Mexico & 3 \\
\hline The Netherlands & 7 \\
\hline New Zealand & 12 \\
\hline Portugal & 4 \\
\hline Serbia & 2 \\
\hline South Africa & 7 \\
\hline South Korea & 5 \\
\hline Spain & 1 \\
\hline Sri Lanka & 1 \\
\hline Thailand & 1 \\
\hline Turkey & 2 \\
\hline United States & 19 \\
\hline Uruguay & 1 \\
\hline Venezuela & 1 \\
\hline Total & 313 \\
\hline
\end{tabular}

The survey was web-based for simplification and to ease data consolidation. SurveyMonkey (SurveyMonkey Inc.) was used for data collection, and the survey was available in English only, as preferred by all NMGI participating organizations. Because the survey was international, the questions had to be carefully worded to reduce confusion and frustration for participants whose first language is not English.

Participation in the survey was by invitation from the NMGI societies and organizations. Each society managed the participation of its members or the people it was representing.

NMGI Survey Results. The survey was open for approximately 1 mo (from July 21, 2014, until August 19, 2014). There were 335 responders, but after elimination of test surveys, partially completed surveys, and duplicate surveys, the final number of responders was 313. The reported results are from these 313 completed surveys, even though some of them had responses that appeared to be inaccurate. For example, some responses were outliers, possibly because of a typographic error or a responder's inability to clearly understand the question. However, if a survey had one apparently inaccurate response but seemed to have reasonable responses to the other questions, the survey was included in the reported results since it was not possible to determine whether the entire survey was inaccurate. Because such outliers may skew the data, the median and interquartile ranges (25th to 75 th percentiles) are reported rather than the mean and SD.

The 313 responders were from 29 countries (Table 3). The method of distributing the survey within a country varied. For some countries, all members of the pertinent national nuclear medicine society were included, whereas for other countries only a select number of hospitals were contacted. As a result, the 5 countries with the most responders were Japan (98), Australia (46), China (33), Italy (21), and the United States (19). Therefore, the responders were organized into 7 regions: Asia (not including Japan) (with 40 [12.8\%] responding sites), Australia/New Zealand (58 [18.5\%]), EANM (i.e., the member nations of the EANM) (77 [24.6\%]), Japan (98 [31.3\%]), Latin America (6 [1.9\%]), North America (27 [8.6\%]), and South Africa (7 [2.2\%]). This variability in response among countries and regions may limit the accuracy of the survey results and the ability to generalize them. However, we still believe that these data provide insight into the global practice of pediatric nuclear medicine. Ninety-three percent of the responders indicated that their practice included general nuclear medicine (with or without PET/CT or PET), whereas $7 \%$ indicated that they did not have a general nuclear medicine practice but performed only PET/CT or PET. Figure 3 shows 2 histograms of the number of studies performed on pediatric patients at each site. The median and mean numbers of procedures on pediatric patients were 100 and 306, respectively, indicating a very skewed distribution. Most sites performed a small number of such studies, and a few sites performed many

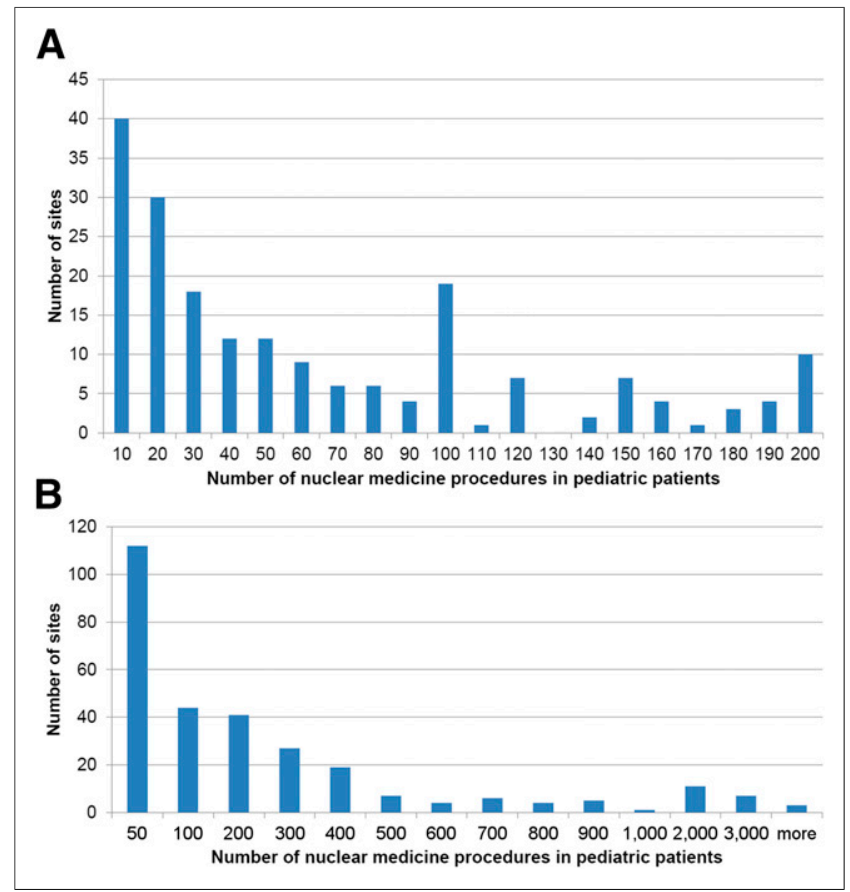

FIGURE 3. Number of nuclear medicine procedures in pediatric patients per year as function of site. (A) Expanded plot for sites performing less than 200 procedures in pediatric patients per year. (B) Plot of number of procedures in pediatric patients for all sites. 
TABLE 4

The 5 General Nuclear Medicine Procedures Most Commonly Performed on Children at the Reported Sites

\begin{tabular}{|c|c|}
\hline Procedure & $n$ \\
\hline Bone scan (e.g., 99mTc-MDP) & $159(21.2 \%)$ \\
\hline Renogram (e.g., 99mTc-MAG3) & $148(19.7 \%)$ \\
\hline $\begin{array}{l}\text { Renal scarring/differential function } \\
\text { (e.g., } 99 \mathrm{~m} T \mathrm{Tc}-\mathrm{DMSA})\end{array}$ & $137(18.2 \%)$ \\
\hline $\begin{array}{l}\text { Neuroendocrine tumor imaging } \\
\left({ }^{(23 \mid-M I B G)}\right.\end{array}$ & $46(6.1 \%)$ \\
\hline Thyroid scan & $40(5.3 \%)$ \\
\hline Meckel diverticulum (e.g., ${ }^{99 m T c-O_{4}}$ ) & $38(5.1 \%)$ \\
\hline Cerebral perfusion scintigraphy & $34(4.5 \%)$ \\
\hline Hepatobiliary & $28(3.7 \%)$ \\
\hline Tumor imaging ( $\left.{ }^{67} \mathrm{Ga}\right)$ & $24(3.2 \%)$ \\
\hline $\begin{array}{l}\text { Gastroesophageal reflux } \\
\text { (e.g., } 99 \mathrm{mTC} \text {-sulfur colloid) }\end{array}$ & $20(2.7 \%)$ \\
\hline
\end{tabular}

more. With respect to PET, $48 \%$ of the sites did not perform PET on children, and $51 \%$ performed PET with a hybrid PET/CT scanner. Only $1 \%$ performed PET with a PET-only scanner that had no CT component.

The sites were asked to rank from most common to least common their 5 most commonly performed general nuclear medicine procedures on children, not including ${ }^{18} \mathrm{~F}-\mathrm{FDG}$ PET (Table 4). The 3 most common procedures were ${ }^{99 \mathrm{~m}} \mathrm{Tc}$ bone scanning, ${ }^{99 \mathrm{~m}} \mathrm{Tc}$ renography, and ${ }^{99 \mathrm{~m}} \mathrm{Tc}-\mathrm{DMSA}$ imaging of renal scarring and differential function. These preferences varied regionally (Table 5), although ${ }^{99 \mathrm{~m}} \mathrm{Tc}$ renography was among the 3 most common procedures in all 7 regions and ${ }^{99 \mathrm{~m}} \mathrm{Tc}$ bone scanning was among the 3 most common procedures in 6 regions.

Figures 4-7 plot regional data for the 2 hypothetical pediatric patients (5-y-old boy weighing $20 \mathrm{~kg}$ and $110 \mathrm{~cm}$ tall; $10-\mathrm{y}$-old girl weighing $30 \mathrm{~kg}$ and $140 \mathrm{~cm}$ tall) for the 3 most common procedures, that is, ${ }^{99 \mathrm{~m}} \mathrm{Tc}$ bone scan, ${ }^{99 \mathrm{~m}} \mathrm{Tc}$ renogram, and ${ }^{99 \mathrm{~m}} \mathrm{Tc}-\mathrm{DMSA}$, as well as for ${ }^{18} \mathrm{~F}-\mathrm{FDG}$ torso PET. Also shown on these figures are the administered activities that would have been recommended for these hypothetical patients by the North American consensus guidelines (labeled SNMMI), the EANM pediatric dosage card, and the Japanese consensus guidelines (labeled JSNM). For ${ }^{99} \mathrm{~m}$ Tc bone scanning, the EANM and JSNM recommendations coincide; the line in Figure 4 is therefore the same for both. For ${ }^{99 \mathrm{~m}} \mathrm{Tc}$ renography, the North American guidelines recommend separate values for studies performed with and without the renal flow component. In Figure 5, these are shown as 2 lines of different colors. For ${ }^{18}$ F-FDG, the North American guidelines recommend a range of activities, which is shown by a shaded area (Fig. 7). Table 6 lists the median and interquartile range for all cases displayed in Figures 4-7. In addition, for the 3 regions that have current guidelines for administered activities in children, the percentage of sites that are exactly in compliance or are within $20 \%$ of the recommended value from their respective guidelines are reported in Table 7.

In general, the 3 regions that have current guidelines for administered activities in children are consistent with their own guidelines. In practically all of these cases, the mode (or most common response) coincides with the value or range of values recommended by their respective guidelines. However, there is also a wide variation about the modal and median values. There were major outliers for some of the values, most likely due to typographic errors. In all cases, South Africa shows less variation than the other regions, perhaps because this region consists of a single nation. In addition, South Africa tends to be in compliance with the EANM dosage card. For ${ }^{99 \mathrm{~m}} \mathrm{Tc}$ bone scanning (Fig. 4), all regions except South Africa demonstrate a similar variation. For ${ }^{99 \mathrm{~m}} \mathrm{Tc}$ renography (Fig. 5) in the 5-y-old, the mode of the North American region corresponds to the recommended administered activity for studies with the flow component. Australia/New Zealand and EANM tend to demonstrate higher variation than the other regions for this procedure. For ${ }^{99 \mathrm{~m}}$ Tc-DMSA imaging (Fig. 6), Latin America, North America, and South Africa show less variation than the other regions. Lastly, Asia and EANM show the largest variation for ${ }^{18}$ F-FDG (Fig. 7).

Of the 313 responders, 129 answered questions about the acquisition of CT in the context of PET/CT. Seventy-two percent

TABLE 5

Regional Variation in the 5 Procedures Most Commonly Performed on Pediatric Patients

\begin{tabular}{|c|c|c|c|c|c|}
\hline Region & Most common & $\begin{array}{l}\text { Second most } \\
\text { common }\end{array}$ & $\begin{array}{l}\text { Third most } \\
\text { common }\end{array}$ & $\begin{array}{l}\text { Fourth most } \\
\text { common }\end{array}$ & $\begin{array}{l}\text { Fifth most } \\
\text { common }\end{array}$ \\
\hline Asia & Bone (31\%) & Thyroid (13\%) & Renogram (11\%) & 99mTc-DMSA (11\%) & Hepatobiliary (11\%) \\
\hline $\begin{array}{l}\text { Australia/New } \\
\text { Zealand }\end{array}$ & Bone (29\%) & Renogram (23\%) & 99mTc-DMSA (20\%) & Thyroid (7\%) & Meckel (6\%) \\
\hline EANM & Renogram (27\%) & Bone (22\%) & 99mTc-DMSA (22\%) & 123I-MIBG (8\%) & Meckel/RNC (6\%) \\
\hline Japan & 99mTc-DMSA (21\%) & Renogram (15\%) & Brain SPECT (13\%) & Bone (12\%) & ${ }^{67} \mathrm{Ga}(9 \%)$ \\
\hline Latin America & Bone (30\%) & Renogram (25\%) & 99mTc-DMSA (15\%) & & \\
\hline North America & Bone (27\%) & Renogram (19\%) & 123I-MIBG (15\%) & 99mTc-DMSA (11\%) & Thyroid (7\%) \\
\hline South Africa & Renogram (29\%) & Bone (21\%) & $\begin{array}{l}\text { Gastroesophageal } \\
\text { reflux }(17 \%)\end{array}$ & & \\
\hline
\end{tabular}

$\mathrm{RNC}=$ radionuclide cystography.

In Latin America, 6 types of procedure were tied at $5 \%$ each as the fourth and fifth most common. 


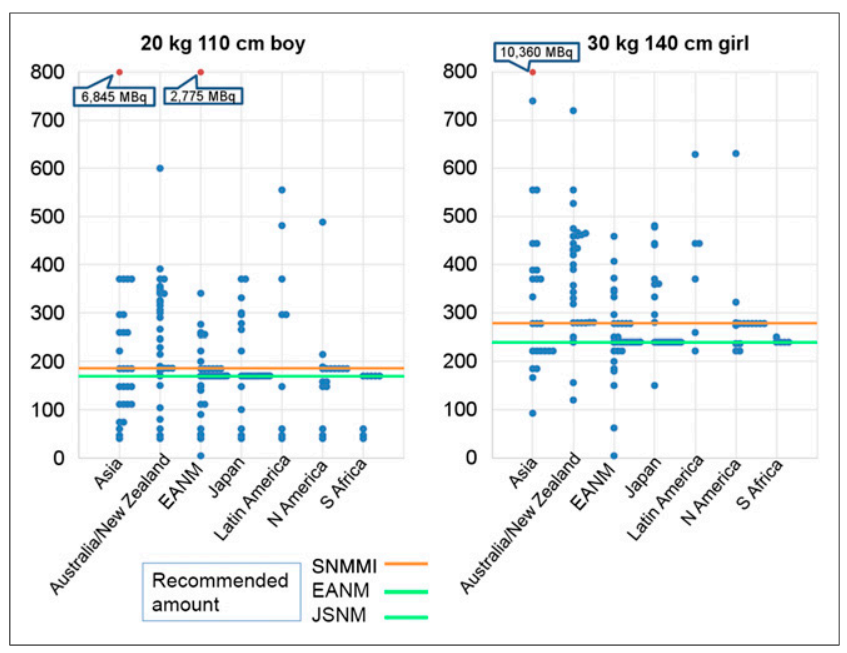

FIGURE 4. Administered activities for $99 \mathrm{mTc}$ bone scans for 2 hypothetical patients (5-y-old $20-\mathrm{kg}$ boy and $10-\mathrm{y}$-old $30-\mathrm{kg}$ girl) as a function of region. Levels recommended by SNMMI, EANM, and JSNM are shown. For ${ }^{99 m}$ Tc bone scans, EANM and JSNM recommendations coincide. This figure demonstrates wide variation within and across regions. For regions with pediatric standards (EANM, Japan, and North America), the most common response was consistent with the recommended amount, but a wide variation was still demonstrated.

of the responders indicated that they use the automatic-exposure feature for the CT acquisition. However, the percentage may be higher because $9 \%$ of the responders did not know whether they use this feature. About one third of responders acquire the CT scan in children as a diagnostic scan with contrast material. One third of the responders use a GE Healthcare PET/CT system, another third use a Siemens system, and 20\% use a Philips system. Less than $3 \%$ specified a different vendor (Toshiba or Shimadsu), and $11 \%$ did not specify the vendor.

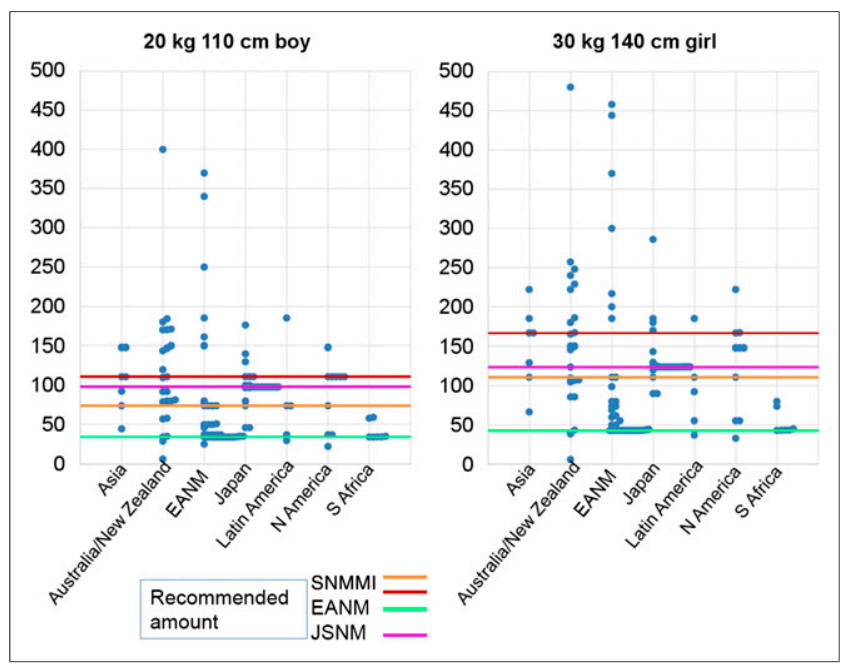

FIGURE 5. Administered activities for ${ }^{99 m T c}$ renograms for 2 hypothetical patients (5-y-old $20-\mathrm{kg}$ boy and $10-\mathrm{y}$-old $30-\mathrm{kg}$ girl) as a function of region. Levels recommended by SNMMI, EANM, and JSNM are shown. SNMMI lists 2 values, one for studies with flow component and another for studies without flow component, both of which are shown. More sites were consistent with value with flow component.

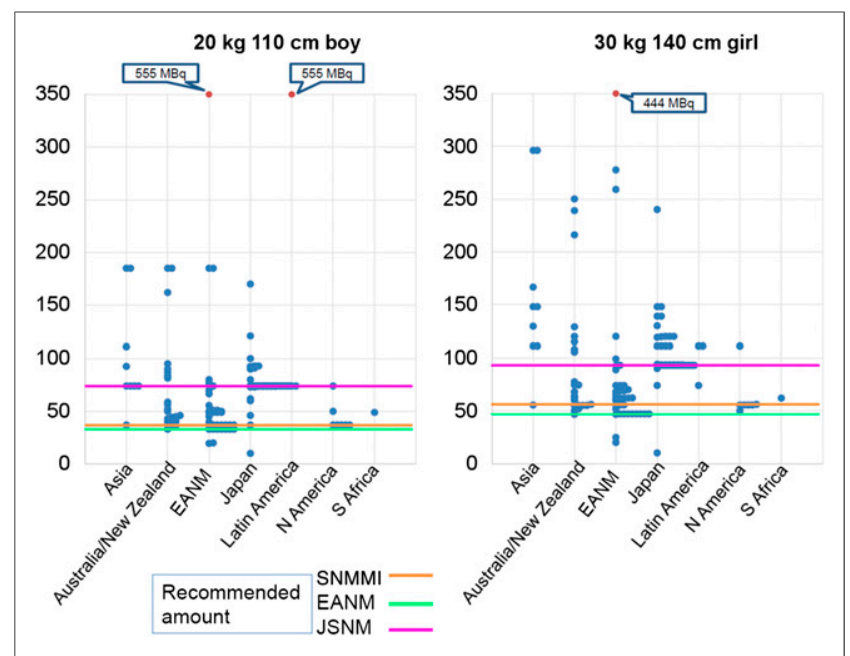

FIGURE 6. Administered activities for imaging of renal cortex using 99mTc-DMSA for 2 hypothetical patients $(5-y$-old $20-\mathrm{kg}$ boy and $10-\mathrm{y}-$ old 30-kg girl) as a function of region. Levels recommended by SNMMI, EANM, and JSNM are shown. This figure demonstrates a wide variation within and across regions. For regions with pediatric standards (EANM, Japan, and North America), the most common response was consistent with the recommended amount, but a wide variation was still demonstrated.

\section{DISCUSSION AND RECOMMENDATIONS}

The unique aspects of pediatric nuclear medicine should be specifically considered, and attention toward image optimization must be stressed for every imaging procedure and every patient. One of the first reports related to pediatric nuclear medicine dates back to 1961 and was a letter published after a group of 75 chairs of pediatric departments in North America had been invited to visit the Division of Biology and Medicine of the Atomic Energy Commission and the Medical Department at the Brookhaven National Laboratory (29). Some sentences in that report of more than 50 years ago could have been written today: "The knowledge

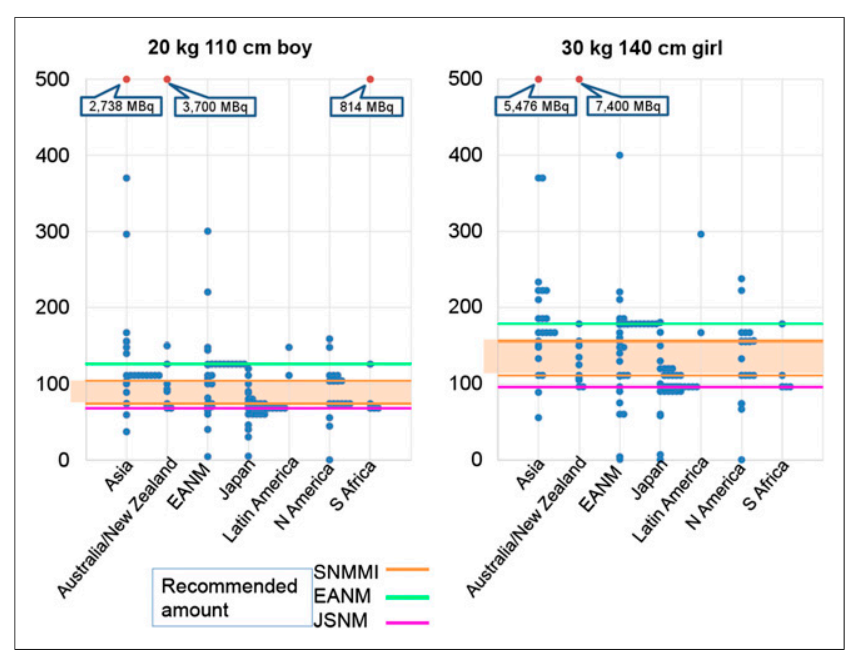

FIGURE 7. Administered activities for ${ }^{18} \mathrm{~F}$-FDG PET scans of torso for 2 hypothetical patients (5-y-old 20-kg boy and 10-y-old 30-kg girl) as a function of region. Levels recommended by SNMMI, EANM, and JSNM are shown. SNMMI recommends a range of administered activities. 
TABLE 6

Administered Activities for 2 Hypothetical Patients and 4 Types of Scan

\begin{tabular}{|c|c|c|c|c|c|c|c|}
\hline Procedure & Asia & $\begin{array}{l}\text { Australia/New } \\
\text { Zealand }\end{array}$ & EANM & Japan & $\begin{array}{l}\text { Latin } \\
\text { America }\end{array}$ & $\begin{array}{c}\text { North } \\
\text { America }\end{array}$ & $\begin{array}{l}\text { South } \\
\text { Africa }\end{array}$ \\
\hline \multicolumn{8}{|l|}{ 99mTc bone scan } \\
\hline 5-y-old 20-kg boy & $185(139,268)$ & $285(186,344)$ & $170(170,185)$ & $170(170,265)$ & $333(296,453)$ & $185(171,186)$ & $170(170,170)$ \\
\hline $10-y$-old $30-k g$ girl & $278(222,389)$ & $395(279,460)$ & $240(240,278)$ & $240(240,359)$ & $407(287,444)$ & $278(255,278)$ & $240(240,240)$ \\
\hline \multicolumn{8}{|l|}{ 99mTc renogram } \\
\hline 5-y-old $20-\mathrm{kg}$ boy & $111(83,130)$ & $101(74,155)$ & $37(34,74)$ & $98(98,99)$ & $74(37,74)$ & $111(46,111)$ & $34(34,47)$ \\
\hline $10-y$-old $30-\mathrm{kg}$ girl & $167(120,178)$ & $146(86,186)$ & $45(43,80)$ & $124(124,125)$ & $93(56,111)$ & $148(69,162)$ & $44(43,60)$ \\
\hline \multicolumn{8}{|l|}{$\begin{array}{l}\text { 99mTc-DMSA renal } \\
\text { scan }\end{array}$} \\
\hline $5-\mathrm{y}$-old $20-\mathrm{kg}$ boy & $74(74,111)$ & $50(41,86)$ & $49(37,51)$ & $74(74,74)$ & $74(74,74)$ & $37(37,44)$ & $49(49,49)$ \\
\hline $10-y$-old $30-\mathrm{kg}$ girl & $148(111,167)$ & $68(55,112)$ & $62(47,74)$ & $93(93,111)$ & $111(93,111)$ & $56(56,56)$ & $62(62,62)$ \\
\hline \multicolumn{8}{|l|}{$\begin{array}{l}\text { 18F-FDG torso PET } \\
\text { scan }\end{array}$} \\
\hline 5-y-old 20-kg boy & $111(94,125)$ & $82(71,98)$ & $111(73,126)$ & $68(68,74)$ & $130(120,139)$ & $89(74,109)$ & $68(68,74)$ \\
\hline $10-y$-old 30-kg girl & $167(149,215)$ & $118(106,146)$ & $167(111,178)$ & $96(96,111)$ & $231(199,264)$ & $144(111,164)$ & $96(96,107)$ \\
\hline
\end{tabular}

Data are median administered activity (MBq), followed by 25th and 75th percentiles in parentheses.

that [the use of radioactive isotopes] in children may be associated with both real and unpredictable hazards has led to hesitation and confusion on the part of the pediatrician. On the one hand he is tempted to make use of a new tool which may lead to earlier diagnosis, shorten hospitalization, and point the way to clear-cut approaches to therapy. On the other hand, he is restrained by concern about the possible late effects which may follow exposure of a young growing organism to radiation." Thousands of papers were subsequently published on this topic, particularly on administered dose in relation to image quality and patient benefit. We know that published data and scientific guidelines are abundant but not always harmonized; the NMGI has highlighted the areas that need to be addressed and their levels of priority.

Based on this initiative, the following observations and conclusions were made. The value of pediatric nuclear medicine is clearly recognized; however, care must be taken to ensure that these studies are applied appropriately in those patients who can best benefit. Much information is available both in print and online about the appropriate use of nuclear medicine in children as well as the current understanding of radiation dosimetry in these patients. Nuclear medicine professionals who image children should take advantage of these materials to be better informed

TABLE 7

Compliance in the 3 Regions (Japan, EANM, and North America) That Have Established Pediatric Guidelines

\begin{tabular}{|c|c|c|c|c|c|c|}
\hline \multirow[b]{3}{*}{ Procedure } & \multicolumn{6}{|c|}{ Respective percentage compliance with... } \\
\hline & \multicolumn{2}{|c|}{ JSNM guidelines } & \multicolumn{2}{|c|}{ EANM guidelines } & \multicolumn{2}{|c|}{ SNMMI guidelines } \\
\hline & $100 \%$ & $20 \%$ & $100 \%$ & $20 \%$ & $100 \%$ & $20 \%$ \\
\hline \multicolumn{7}{|l|}{ 99mTc bone scan } \\
\hline 5-y-old 20-kg boy & $60.0 \%$ & $64.0 \%$ & $43.2 \%$ & $70.3 \%$ & $46.7 \%$ & $93.3 \%$ \\
\hline 10-y-old 30-kg girl & $56.0 \%$ & $64.0 \%$ & $36.8 \%$ & $68.4 \%$ & $46.7 \%$ & $93.3 \%$ \\
\hline \multicolumn{7}{|l|}{ 99mTc renogram } \\
\hline 5-y-old 20-kg boy & $54.8 \%$ & $80.6 \%$ & $39.5 \%$ & $81.4 \%$ & $50.0 \%$ & $50.0 \%$ \\
\hline 10-y-old 30-kg girl & $61.3 \%$ & $77.4 \%$ & $40.5 \%$ & $57.1 \%$ & $30.0 \%$ & $50.0 \%$ \\
\hline \multicolumn{7}{|c|}{${ }^{99 m}$ Tc-DMSA renal scan } \\
\hline 5-y-old 20-kg boy & $64.4 \%$ & $75.6 \%$ & $18.4 \%$ & $39.5 \%$ & $71.4 \%$ & $71.4 \%$ \\
\hline 10-y-old 30-kg girl & $57.8 \%$ & $71.1 \%$ & $24.3 \%$ & $35.1 \%$ & $71.4 \%$ & $85.7 \%$ \\
\hline \multicolumn{7}{|c|}{${ }^{18} \mathrm{~F}-\mathrm{FDG}$ torso PET scan } \\
\hline 5-y-old 20-kg boy & $39.5 \%$ & $76.3 \%$ & $30.3 \%$ & $51.5 \%$ & $58.8 \%$ & $82.4 \%$ \\
\hline 10-y-old 30-kg girl & $39.5 \%$ & $71.1 \%$ & $27.3 \%$ & $57.6 \%$ & $47.1 \%$ & $70.6 \%$ \\
\hline
\end{tabular}


and thus better serve their pediatric patients. There remain gaps in knowledge about the biokinetics and radiation dosimetry associated with the use of nuclear medicine in children, and there is limited information on the potential risk of adverse effects from ionizing radiation in children at the dose levels used in nuclear medicine. More complete understanding of these issues would allow for better optimization of pediatric nuclear medicine. There remains a wide variability in the practice of pediatric nuclear medicine across the globe. Clinical sites in regions that have guidelines on administered activities in children tend to be consistent with those guidelines, although some wide variations still exist.

As a result of these observations, the following recommendations are made. Regions that currently do not have pediatric guidelines for administered activities should either develop their own or officially adopt one of the existing sets of guidelines. Regions that have guidelines should expand them to include all nuclear medicine procedures practiced on children and should continue to strive for harmonization among these guidelines. The administered activity for pediatric patients should be incorporated into the auditing process for nuclear medicine sites, whether through local or country-based programs or by methods such as the IAEA QUANUM (Quality Management Audits in Nuclear Medicine Practices) program. Pediatric dose recommendations should be incorporated into formal training curricula and recertification programs for all nuclear medicine professionals. All organizations involved in nuclear medicine should disseminate the NMGI findings and recommendations to their members and constituents. The appropriate use of pediatric nuclear medicine and adherence to guidelines on administered activities for children and adolescents should be actively promoted to a wide audience. This initiative can pave the way not only toward further studies on dose optimization in pediatric nuclear medicine, but also toward greater awareness of the problems and opportunities in the medical community.

\section{CONCLUSION}

The NMGI has demonstrated that a community of medical practitioners and scientists can successfully join in a global effort to provide the best possible treatment for their patients. We will strive to continue this initiative with even more enthusiasm and commitment.

\section{REFERENCES}

1. Fahey FH, Bom H, Chiti A. at al. Standardization of administered activities in pediatric nuclear medicine: a report of the first Nuclear Medicine Global Initiative project, part 1-statement of the issue and a review of available resources. J Nucl Med. 2015;56:646-651.

2. Shore RM, Hendee WR. Radiopharmaceutical dosage selection for pediatric nuclear medicine. J Nucl Med. 1986;27:287-298.

3. Hsiao EM, Cao X, Zurakowski D, et al. Reduction in radiation dose in mercaptoacetyltriglycerine renography with enhanced planar processing. Radiology. 2011;261:907-915.

4. Fahey F, Stabin M. Dose optimization in nuclear medicine. Semin Nucl Med. 2014;44:193-201.

5. Treves ST, Falone AE, Fahey FH. Pediatric nuclear medicine and radiation dose. Semin Nucl Med. 2014;44:202-209.
6. Alessio AM, Kinahan PE, Manchanda V, et al. Weight-based, low-dose pediatric whole-body PET/CT protocols. J Nucl Med. 2009;50:1570-1577.

7. Sgouros G, Frey EC, Bolch WE, et al. An approach for balancing diagnostic image quality with cancer risk: application to pediatric diagnostic imaging of 99mTc-dimercaptosuccinic acid. J Nucl Med. 2011;52:1923-1929.

8. Botros GM, Towson JE, Smart RC. Updated paediatric diagnostic reference activities for nuclear medicine procedures in Australia and New Zealand derived from the 2009 survey. ANZ Nucl Med. 2010;41:12-18.

9. Treves ST, Davis RT, Fahey FH. Administered radiopharmaceutical doses in children: a survey of 13 pediatric hospitals in North America. J Nucl Med. 2008;49:1024-1027.

10. Gelfand MJ, Parisi MT, Treves ST. Pediatric radiopharmaceutical administered doses: 2010 North American Consensus Guidelines. J Nucl Med. 2011;52:318-322.

11. Treves ST, Parisi MT, Gelfand MJ. Pediatric radiopharmaceutical doses: new guidelines. Radiology. 2011;261:347-349.

12. Lassmann M, Biassoni L, Monsieurs M, Franzius C, Jacobs F. The new EANM paediatric dosage card. Eur J Nucl Med Mol Imaging. 2007;34:796-798.

13. Lassmann M, Biassoni L, Monsieurs M, Franzius C. The new EANM paediatric dosage card: additional notes with respect to F-18. Eur J Nucl Med Mol Imaging. 2008;35:1666-1668.

14. Lassmann M, Biassoni L, Monsieurs M, Franzius C, Jacobs F. The new EANM paediatric dosage card. Eur J Nucl Med Mol Imaging. 2008;35:1748.

15. Koizumi K, Masaki $\mathrm{H}$, Matsuda $\mathrm{H}$, et al. Japanese consensus guidelines for pediatric nuclear medicine. Part 1: Pediatric radiopharmaceutical administered doses (JSNM pediatric dosage card). Part 2: Technical considerations for pediatric nuclear medicine imaging procedures. Ann Nucl Med. 2014;28:498-503.

16. Administration of Radioactive Substances Advisory Committee. Notes for Guidance on the Clinical Administration of Radiopharmaceuticals and Use of Sealed Radioactive Sources. Chilton, England: Health Protection Agency for the Administration of Radioactive Substances Advisory Committee; 2006 (revised 2014).

17. Rixham PA, Roberts G. The new EANM paediatric dosage card: how does it affect UK centres working under the ARSAC guidelines? Nucl Med Commun. 2009;30:319-320

18. Lassmann M, Treves ST. EANM/SNMMI Paediatric Dosage Harmonization Working Group. Paediatric radiopharmaceutical administration: harmonization of the 2007 EANM paediatric dosage card (version 1.5.2008) and the 2010 North American consensus guidelines. Eur J Nucl Med Mol Imaging. 2014;41: 1036-1041.

19. Treves ST, Lassmann M. International guidelines for pediatric radiopharmaceutical administered activities: EANM/SNMMI Pediatric Dosage Harmonization Working Group. J Nucl Med. 2014;55:869-870.

20. Piepsz A, Hahn K, Roca I, et al. A radiopharmaceuticals schedule for imaging in paediatrics. Eur J Nucl Med. 1990;17:127-129.

21. Jacobs F, Thierens H, Piepsz A, et al. Optimised tracer-dependent dosage cards to obtain weight-independent effective doses. Eur J Nucl Med Mol Imaging. 2005;32:581-588.

22. Grant FD, Gelfand MJ, Drubach LA, et al. Radiation doses for pediatric nuclear medicine studies: comparing the North American consensus guidelines and the pediatric dosage card of the European Association of Nuclear Medicine. Pediatr Radiol. 2015;45:706-713.

23. Karasawa K, Kamiyama H, Hashimoto T, Koizumi K. Survey questionnaire of pediatric nuclear medicine examinations in 14 Japanese institutes. Kaku Igaku. 2013;50:61-67.

24. Helton JD, Barron TL, Hung JC. Criteria for determining optimal pediatric dosage for a diagnostic nuclear medicine procedure. J Nucl Med Technol. 1996;24: $35-38$.

25. Smith T, Gordon I. An update of radiopharmaceutical schedules in children. Nucl Med Commun. 1998;19:1023-1036.

26. Warbey VS, Schleyer PJ, Barrington SF, O'Doherty MJ. The new EANM paediatric dosage card: does it conform to ALARA for PET/CT? Eur J Nucl Med Mol Imaging. 2007;34:1881-1882.

27. Holm S, Borgwardt L, Loft A, et al. Paediatric doses: a critical appraisal of the EANM paediatric dosage card. Eur J Nucl Med Mol Imaging. 2007;34: 1713-1718.

28. Fahey FH, Ziniel SI, Manion D, Treves ST. Effects of image gently and the North American guidelines: administered activities in children at 13 North American pediatric hospitals. J Nucl Med. 2015;56:962-967.

29. Medovy H. Pediatrics and nuclear medicine. J Pediatr. 1961;59:161-163. 